\title{
Lawrence Berkeley Laboratory FY 1992 Site Development Plan
}

\author{
Lawrence Berkeley Laboratory \\ University of California \\ Berkeley, California 94720
}

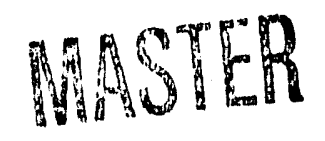

Distribution of this oocument is unt 


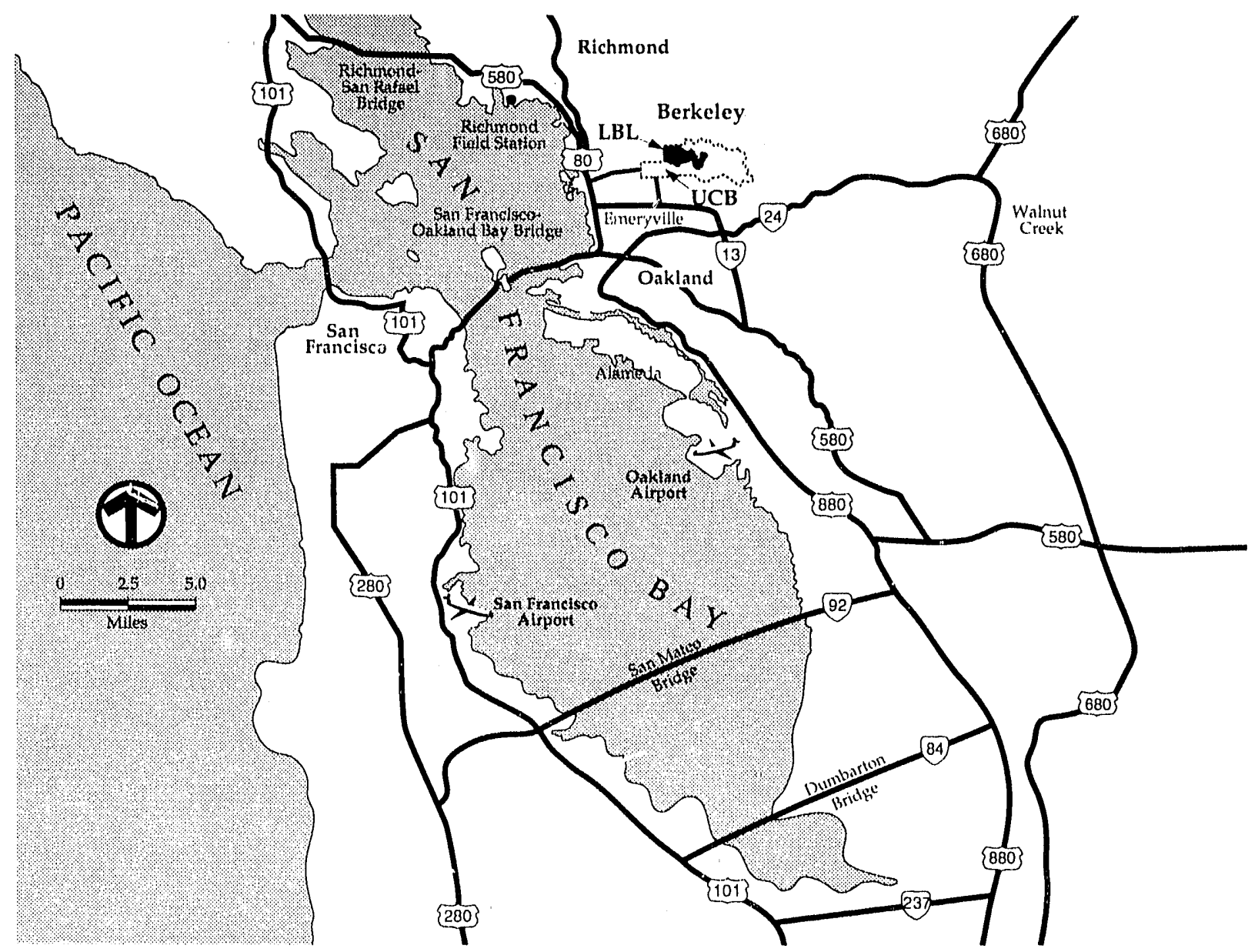

Lawrence Berkeley Laboratory is located in the hills overlooking the San Francisco Bay in close proximity to major highways and regional airports. 


\section{Preface}

The Lawrence Berkeley Laboratory 1992 Site Development Plan (SDP) provides analysis and policy guidance for the effective use and orderly development of land and facilities at the LBL main site. The SDP directly supports LBL's role as a multiprogram national laboratory operated by the University of California (UC) for the Department of Energy (DOE). It is a concise policy document, prepared in compliance with DOE Order 4320.1B and based on revisions to the 1991 Technical Site Information (TSI). It also serves as the current DOE framework for the implementation of the 1987 Long Range Development Plan (LRDP) approved by the Regents of the University of California. The SDP is updated annually, with periodic major revisions consistent with DOE policy and approved plans of the Regents. The plan is reviewed and approved by the DOE Field Office at San Francisco. The specific purposes of the SDP are to:

- Summarize the mission and community setting of the Laboratory;

- Describe program trends and projections and future resource requirements;

- Describe site planning goals and future facilities and land uses; and

- Describe site planning issues and potential solutions.

The SDP concisely expresses the policies for future development based on planning concepts, the anticipated needs of research programs, and site potential and constraints. The 1992 Technical Site Information document and other planning data provide detailed support for the plans identified in this document.

Preparation of the SDP was coordinated by the Office for Planning and Development with technical support and data preparation by the Plant Engineering Department. Programmatic data and information are from program divisions and technical resource divisions, including the Environment, Health \& Safety Division. The 1992 SDP is consistent with approved university guidelines and future building area, land use, and population projections identified in the 1987 LRDP and the 1987 Site Development Plan Environmental Impact Report prepared under the California Environment Quality Act. 


\section{Table of Contents}

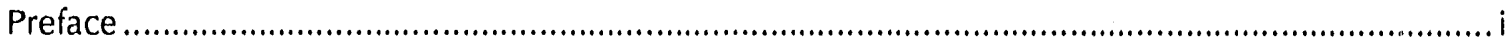

Sections

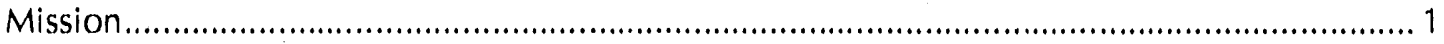

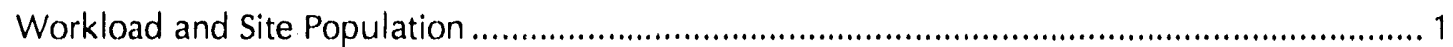

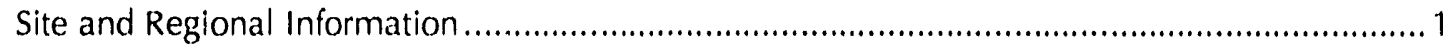

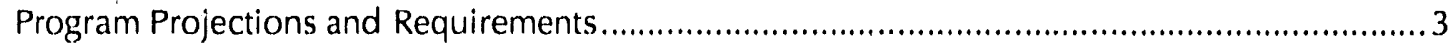

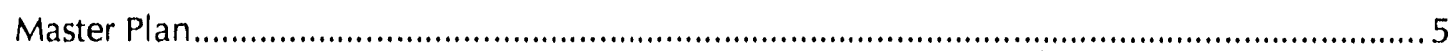

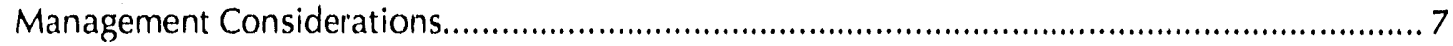

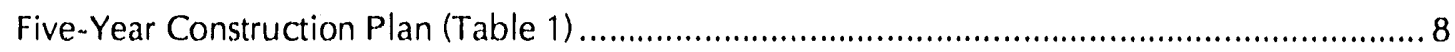

Appendix

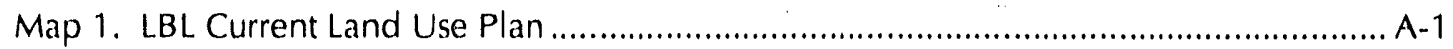

Map 2. LBL Building Locations and Functional Areas................................................... A-2

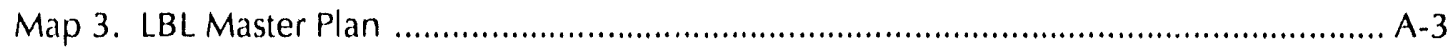

Map 4. Proposed major construction projects (FY 1993-FY 1995) ...................................... A-4 


\section{Mission}

The Laboratory, established in 1931 by Ernest $O$. Lawrence as a single-purpose accelerator-based University research facility, has evolved into a multiprogram national laboratory operated by the $U C$ for the DOE with a mission to:

- Perform leading multidisciplinary research in the energy sciences, general sciences, and life sciences in a manner that ensures employee and public safety and the protection of the environment. The energy sciences include materials research, chemistry, geology, and conservation and renewable energy research. The general sciences include nuclear and highenergy physics and accelerator research. The life sciences include cell and molecular biology, genetics, and biomedical research.

- Develop and operate unique national experimental facilities for use by qualified investigators from throughout the world, including the Bevalac, the 88-Inch Cyclotron, the National Center for Electron Microscopy, and the National Tritium Labeling Facility. The Advanced Light Source (ALS) is scheduled for completion in 1993.

- Educate and train future generations of scientists and engineers. 500 graduate students pursue research at the $\mathrm{LBL}$ with about 100 students receiving advanced degrees each year. Precollege programs are conducted for science educators and students.

- Foster productive relationships with industry. The Center for Advanced Materials and the Center for X-Ray Optics are examples of collaborations with industry. Technology transfer programs promote the application of research results.

\section{Workload and Site Population}

LBL programs are primarily supported by the DOE Office of Energy Research (62\%). The largest programs are in Basic Energy Sciences, Nuclear Physics, High Energy Physics, and Health and Environmental Research. Conservation and Renewable Energy $(6 \%)$ supports studies in building energy conservation, energy storage, and solar and geothermal energy. Other DOE-sponsored programs (15\%) include research on the Superconducting Super Collider (SSC), radioactive waste disposal, and fossil energy. Work for other agencies and institutions (17\%) is primarily for the National Institutes of Health, Department of Defense, States, and private industry. Projected operating costs for FY 1992 are $\$ 210 \mathrm{M}$.

Laboratory Population. In 1991, the Laboratory's employee population consisted of 3,330 full- and part-time employees. These employees included 795 staff scientists, 220 faculty scientist; 1,610 technical staff and administrative staff; and 705 graduate students, undergraduates, and postdoctoral fellows. There were 2,570 full-time equivalent (FTE) positions. LBL maintains a register of official guests, updated monthly, which contained 1,400 registered guests in 1991. About 610 of these guests were on site at any one time, so that total Laboratory population was 3,940. Of this total, 3055 were located at the main site, 765 located in UC Berkeley Campus buildings, and 120 located in off-site leased buildings.

\section{Site and Regional Information}

The 134-acre Laboratory site, located within 1180 acres of UC land, is leased by DOF through a series of 50-year lease agreements. The Laboratory is in Alameda County (population 1,280,00()), with the eastern section in the City of Oakland $(370,000)$ and the western section in the City of Berkeley $(103,000)$. Although the area is largely urban and is served by interstate highways and an extensive public transit system, the Laboratory site has hilly topography with areas of steep slopes and trees that give $\mathrm{LBL}$ a rural character. 
- Land Use and Topography. The Laboratory site is zoned governmental and institutional by the cities of Berkeley and Oakland. On all sides of the Laboratory is a buffer zone of University land. The SDP provides for landscape buffer zones between LBL facilities and the Laboratory boundary and includes guidelines to ensure compatibility with land use outside the University buffer zone. The steep topography limits new building sites and makes building rehabilitation, replacement, and siting for efficient land use a priority (see Appendix, Map 1).

- Transportation Systems. The Laboratory and the cities of Oakland and Berkeley are served by a network of public transit systems, three major airports (San Francisco, Oakland, and San Jose), two railroads, and a network of interstate freeways and state highways. In addition, LBL operaies shuttle buses around the site and between the Laboratory and the UC Berkeley Campus and the downtown Berkeley Bay Area Rapid Transit (BART) station.

- Public Utilities and Community Services. Electricity and natural gas are provided by the Pacific Gas and Electric Company (PG\&E). Water is supplied by the East Bay Municipal Utilities District (EBMUD). Reservoirs adjacent to LBL and on-site storage tanks provide water for emergency needs. The Laboratory provides its own police and fire protection services, which on occasion provide emergency assistance to the University and the City of Berkeley. Under mutual aid agreements LBL coordinates other activities with the surrounding communities: (1) a Hill Area Fire Safety Program, (2) an LBL. Traffic and Parking Management Plan, and (3) a plan to ensure preservation of historic buildings.

- Buildings. LBL research and support activities are conducted in structures totaling 2.02 million gross sq. ft. (gsf). In FY 1992 this includes: 81 permanent buildings, 110 trailers and temporary structures, and buildings under construction on the main site of 1.62 million gsf (see Appendix, Map 2); 0.26 million gsf on the UC Berkeley Campus; and 0.14 million gsf leased off-site. In FY 1992 the average age of the main-site buildings is 30 years. The quality of building space is rated as follows: (a) adequate, 595,300 gsf; (b) substandard, can be made adequate, 811,200 gsf; and (c) substandard, cannot be made adequate 214,600 gsf. Improvements in the condition of the substandard space, a part of a long-term rehabilitation and modernization program, would enhance conditions for safely and efficiently achieving the Laboratory's mission.

- Utilities. LBL's utilities distribution systems (mechanical, electrical, and communications) are all underground. Many portions were initially sized to serve large accelerators and can meet present and future requirements. However, aged segments require rehabilitation or replacement to improve environmental protection, flexibility, and reliability.

LBL's power-distribution system consists of 24 substations and 20 miles of $12-\mathrm{kV}$ cable. The electrical power is distributed underground from the centrally located Grizzly Peak Substation, which gentrally has spare capacity. The water distribution system consists of a total of $34,62.5$ lineal feet of line, with pressure alarms, hydrants, flow meters, back flow preventers, and storage tanks. LBL has 400,000 gallons of on-site emergency storage equipped with automatic starting fire pumps, and two municipal water storage reservoirs are nearby. The sanitary sewer system consists of 18,385 lineal feet of sewers with waste holding tanks and monitoring stations and empties into the EBMUD Sewer Mains at Hearst Street and in Strawberry Canyon. The Natural Cias System consists of $15,320 \mathrm{ft}$ of service line, pressure reducing stations, seismic safety shutoff valves, integrating flow meters, and other gas valves and manifolds that interface with the main PG\&E supply.

- Circulation and Traffic. LBL traffic circulates along an east-west central serpentine road, with north and south loops. Gates to the Laboratory are located at the ends of the central east-west road. These main roads were designed in the 1940s and early 1950s and no longer meet construction or safety standards. Nearly 7,000 vehicle trips per day are made to $L B L$, including 70 shuttle-bus trips off site and 98 on site. The off-site shuttle car ies an average of about 1,350 passengers per day. Parking space is provided for 1,800 employee vehicles, with 1.7 employees and visitors per parking space. 


\section{Program Projections and Requirements}

Mission Projections. LBL's research and support trends are assessed and described in the FY 19921997 Institutional Plan, published in November 1991. The major changes in mission activity are in response to DOE's national programs in the Office of Basic Energy Sciences (BES) and the Office of Health and Environmental Research (OHER). In response to national needs for high-brightness synchrotron radiation facilities, LBL is constructing the ALS, which will be completed in FY 1993, and will provide the world's brightest beams of soft $x$-ray and ultraviolet light for use in materials science research, chemistry, biology, and other fields. When completed and fully operational, the ALS will provide ports for up to 45 end stations, with an on-site user population of up to 250 scientists at any one time. The Laboratory must provide the research and facilities infrastructure to support this user community.

Also supporting research in the BES Division of Chemical Sciences, LBL, in coordination with other national laboratories, has prepared conceptual designs for a Chemical Dynamics Research Laboratory for advanced studies in reaction science and combustion chemistry. Other BES future mission projects include improvements to the National Center for Electron Microscopy and strengthened programs in the Center for Advanced Materials. The following are other programmatic growth areas in the energy sciences:

- Materials science research growth areas will support key materials of national interest, including materials with reduced dimensionality, high-temperature superconductors, semiconductors, composites, ceramics, light alloys, and polymers. The Laboratory's Center for Advanced Materials, National Center for Electron Microscopy, and Center for X-Ray Optics will be important elements of a national program directed toward improved materials synthesis and processing.

- Chemistry of inorganic and complex organic molecules will require advanced techniques using intense photon beams, nuclear magnetic resonance (NMR) spectroscopy, and laser spectroscopy. The defined programmatic needs for these techniques including infrared free-electron laser facilities required for reactivity studies of molecular dynamics is an important programmatic projection in the master plan.

- Earth sciences research will include geophysical investigations of the continental crust and physical, chemical, and isotopic studies of geological materials, including petroleum and geothermal reservoirs, and processes involving the transport and Iransformation of chemicals in complex geological structures.

- Energy-use research important to national energy security will emphasize advanced high-efficiency combustion, energy storage, electric lighting, energy-intensive chemical processes, and energy flows through walls and windows. Continued reliance on fossil fuels and nuclear power will intensify problems with emissions and waste disposal.

- Applied Mathematical Sciences including High Performance Computing Initiative and growth in networking and distributed computing.

In Health and Environmental Research, LBL has been designated by the Secretary of Energy as a DOE Human Genome Center. The existing support for human genome research is expected to grow significantly, requiring an expansion of life-sciences-related facilities, and specifically the construction of a Human Genome Laboratory. Programmatic growth areas are the following:

- Physical mapping and eventual sequencing of the human genome will be emphasized, including determination of human genome structure and expression, clonal library preparation, robotics, novel instrumentation, development of advanced computation and pattern-recognition techniques, and medical genetics. 
- Basic research in the molecular and cellular aspects of the control of gene expression, differentiation, DNA repair and carcinogenesis, and genomic stability in human as well as animal models systems will provide tools for an understanding of environmentally related disorders.

- Structural biology research will be directed toward determining the relationstip between the structure of biological macromolecules and their functions. The application of synchrotron radiation and advanced computational techniques will allow the determination of the threedimensional structure of proteins and nucleic acids.

- Biomedical research will continue the application of advanced technology to study, diagnose, and treat human disease through innovations in positron emission tomography (PET), NMR, and charged-particle radiation therapy and radiosurgery. A new Biomedical Isotope Facility will be constructed within existing Laboratory space to advance PET research. Radiobiology research at the Bevalac is expected to continue through the decade in support of the nation's Space Exploration Initiative. However, contingency planning for the Bevalac, for a phased reduction of the Bevalac's nuclear physics program, is underway (see below).

- Environmental- and health-effects research will include atmospheric chemistry and transport, deposition, and ecological effects of combustion products. Studies of sources and transport of chemicals from the subsurface environment will cover contamination of groundwater and radon exposure.

LBL's general sciences programs are developed in conjunction with the high energy and nuclear physics communities and with Federal programs in fusion research. LBL's general sciences includes the following developments:

- Accelerator research will focus on fundamental accelerator physics, accelerator design, and advanced accelerator technology.

- Nuclear physics research will emphasize techniques that probe or alter the state of nuclei to explore nucleonic, hadronic, and quark-gluon matter. The national Gammasphere projec: at the 88 -Inch Cyclotron is essential to understand the physics of nuclear structure. The Bevalac's nuclear physics program will be phased out in the middle of the decade, and unless funding via the Space Exploration Initiative or from another agency is provided, the Bevalac is a candidate for the Decommissioning and Decontamination (D\&D) program. A new collaborative experiment is being planned at the Relativistic Heavy Ion Collider under construction at Brookhaven National Laboratory.

- LBL will continue its high-energy physics research programs at the Tevatron and Stanford Linear Collider (SLC) and at a proposed B-factory program at the Positron-Electron Project (PEP). Further progress will become possible through the construction of the SSC; with the selection of the Solenoidal Detector Collaboration, LBL will play an even larger role.

- National fusion research will continue to emphasize the performance of a fusion system. LBL will continue its leading research in heavy-ion accelerators for fusion-a technology that would employ accelerated beams of ions to ignite fusion fuel pellets. The induction Linac Systems Experiment (ILSE) is the next step for this research at LBL. The development of neutral beams for plasma heating and current drive will continue in support of the magnetic-fusion program and potentially applied to the International Thermonuclear Experimental Reactor.

Laboratory Projected Resources and Workload. Laboratory operating costs are projected to increase from $\$ 210 \mathrm{M}$ in 1992 to $\$ 260 \mathrm{M}$ in 1997 . Total Laboratory funding, including equipment and construction, is projected to increase from $\$ 253 \mathrm{M}$ in 1992 to $\$ 320 \mathrm{M}$ in 1997 . Near-term workload increases are projected, based on the operating budgets of the ALS, human genome program, and initiatives associated with DOE's Division of Chemical Sciences.

Population Projection. The main-site population is projected to increase from 3055 in FY 1991 to approximately 3,590 in FY 1997 . The total projected Laboratory population will increase from 3940 in 
FY 1992 to approximately 4,390 in FY 1997. The long-term projected growth at the site, identified in the $1991 \mathrm{TSI}$, allows for an average daily main-site population of 4100. The potential total Laboratory population (includes main site, UC Berkeley campus, and off-site areas) of 4750 could be obtained within the 20-year master plan (1991 TSI) if national and regional programs require this growth.

\section{Master Plan}

Site planning at the Laboratory reflects long-range institutional goals and values based on the University's management of LBL to support DOE missions. The site development planning objectives are to:

- Evaluate future mission projections and anticipate DOE national research facility needs;

- Ensure a safe and healthful workplace in full compliance with building and fire codes;

- Protect the environment and buffer activities to enhance adjacent land uses;

- Protect the national investment in valuable government-owned research and support facilities;

- Consolidate research and support services through proper siting of new buildings;

- Improve access and communications within and to the Laboratory; and

- Promote energy conservation and cost reductions through efficient building design, location, operation, parking and transportation, and maintenance.

The SDP is based on five LBL site master plan concepts. These concepts accommodate the facilities improvement needs within existing geophysical, environmental, and operational conditions. They provide a basis for understanding and evaluating the more detailed elements of specific projects, planned locations, and other site improvement projections.

The site-planning concepts are to:

- Consolidate activities within seven functional planning areas to enhance efficiency and effectiveness and to provide specialized research facilities;

- Redevelop obsolete buildings and infrastructure, eliminate temporary structures used for permanent functions, and improve building arrangements to increase safety and energy efficiency;

- Concentrate development along the east-west circulation and utilities axis to enhance transportation and service systems, e.g., develop off-road parking and improve pedestrian pathways;

- Improve and maintain perimeter and internal buffer zones to screen noise-generating act vities and minimize potential incompatibility between adjacent operations; and

- Provide off-site facilities for receiving, warehousing, and other support and research artivities suitable for decentralization.

Design guidelines for site development have beel! developed to achieve specific improvements while respecting site constraints and have provided coherence between buildings and their surroundings. These guidelines, described in more detail in the Site Technical Information document, address the following areas: safety considerations; uitilities corridors; building mass, orientation, and exteriors; 
energy and operational efficlency; bullding use flexibility; circulation and parking; topography and grading; landscaping and open space; and guideline conformance review.

Facility and Land Requirements. If the full programmatic capability of the site is developed to meet anticipated national needs in energy technology and supporting research, the sites and buildings identified in this Master Plan would result in a net increase of $0.4 \mathrm{M}$ gsf to the existing main site of the Laboratory, for a total of approximately $2.0 \mathrm{M}$ gsf (see Appendix, Map 3). For comparison, the 1992 total, including current construction, consists of $1.62 \mathrm{M}$ gsf at the main site. The Laboratory's on-site space is now $100 \%$ utilized at an approximate $70 \%$ net to gross area efficiency. The useable on-site space is approximately $1.1 \mathrm{M}$ net square feet. The building utilization efficiency is not projected to change significantly, although the efficiency of land use is expected to improve with the replacement of obsolete single- and two-story buildings with three- to flve-story structures.

Future Land Uses 80.2 acres of the site are currently open space and landscape areas; 77.8 acres would be retained as open space and buffer if all projects identified in the Master Plan were cornpleted. The Master Plan would change the proportion of the LBL main site improved with structures, utilities, or roads from the current $38 \%$ to $42 \%$. Nine buffer zones are employed to maintain the quality of the LRL working environment, with specific planning criteria identified for each buffer zone location.

Future Major Facility Locations and Functional Areas. The functional planning areas are related groupings of facilities that enhance work efficiency and effectiveness. In general, parking is at the perimeter of these areas, and clusters of buildings form the core. The Master Plan identifies changes to all of the functional planning areas to allow for potential research activities and to conform to SDP objectives, planning concepts, and design guidelines. The Master Plan calls for the removal of $0.2 \mathrm{M}$ gsf of buildings and the renovation of $0.8 \mathrm{M}$ gsf of building space. Building sites are planned or reserved for $0.6 \mathrm{Mgsf}$ of new construction.

The natural constraints of the site coupled with the desirability of maintaining efficient programmatic development have led to the delineation of the LBL site into seven functional planning areas. These subdivisions of the site, which are generally identified with specific research programs and/or support facilities, have been individually studied to ensure effective short- and long-range use:

- 88-Inch Cyclotron Research Area, located on a hillside terrace near the main entrance to LBL, includes 53,800 gsf. Functionally, the area will continue to be dedicated entirely to the 88 -Inch Cyclotron and its close support facilities. An 8,600 gsf second floor addition is planned to support the forthcoming national Gammasphere project.

- Central Research and Administration Area houses the LBL Director's Offices and the main divisional offices for Accelerator and Fusion Research, Administration, Earth Sciences, Energy and Environment, Engineering, Information and Computing Sciences, Nuclear Science, Physics, and Planning and Development. It encompasses 489,100 gsf and includes the majority of LBL'c light laboratories and support offices as well as the cafeteria. A shortage of light laboratories and offices for existing programs remains, and a number of laboratory spaces in the Building 50-70 complex art' still used for offices. An important element of the SDP is the construction of economical additions to existing buildings to provide office space that will permit reclamation of valuable laboratory space. Building 90 and its trailer complex currently house Administration, EH\&S, Plant Engineering Department, Energy and Environment, and Engineering Divisions' offices. A seismic rehabilitation of Building 90 is critical to the Master Plan, and since parking is limited in this area the trailers will be removed as replacement office space becomes available.

- Bevalac Accelerator Complex encompasses 355,000 gsf, including the Bevalac, heavy-laboratory experimental areas, cryogenic support facilities, staging areas, associated offices, and facilities for advanced accelerator research and development. The area has an extensive array of support utilities, crane and hoisting equipment, and related resources for future program needs. The Master Plan allows for continued use as a heavy laboratory depending on the specific programmatic needs for nuclear physics, space reseaich, biomedical applications, and heavy-ion fusion research. 
- Light Source Research and Engineering Area encompasses 15 acres and Includes bulldings enclosing 362,600 gsf of space. The dominant feature of this area is the dome of Building 6 , which originally enclosed the 184-Inch Cyclotron and which has been remodeled to contain the ALS (scheduled to be completed in 1993). This area has excellent geographical and geotechnical qualities and natural topography especially suited to bullding sites for high-technology facilities, including the Chemical Dynamics Research Laboratory.

- Materials and Chemistry Research Area encompasses the Materials and Molecular Research Laboratory, the National Center for Electron Microscopy, and the Surface Science and Catalysis Laboratory, totaling 124,000 gsf. Upgrades are proposed to the National Center for Electron Microscopy, and building sites are reserved for future development.

- Shops and Support Facilities Area encompasses the Craft Shops, Supply Services, Transportation, Motor Pool, Mechanical Shops, the Environment, Health and Safety Division, and the National Tritium Labeling Facility, totaling 167,500 gsf. The Hazardous Waste Handling Facility is to be relocated from this area to the east canyon in the Life Sciences Research Areas (below). Consolidation of the support facilities is to continue with the construction of the Safety and Support Services Facility and the Environmental Monitoring \& Industrial Hygiene Building.

- Life Sciences Research Area encompasses 11 acres in the upper reaches of Strawberry Canyon and includes sites for a Human Genome Laboratory and facilities to consolidate research in Cell and Molecular Blology. Existing buildings and new construction of the Hazardous Waste Handling Facility in the east canyon, totaling 69,100 gsf include the Biomedical Laboratory and the Laboratory for Cell Biology. This area has significant potential for future development.

Utilities Systems. LBL is served by electrical and mechanical utilities systems along the east-west site axis and are served by a series of nodes. Many of the utilities systems were initially installed during the 1940s and require upgrades or replacement to achieve improved levels of reliability and service capacity. Many systems have adequate capacity but require extensions or improvements to achieve satisfactory performance and maintenance efficiency.

- Electrical Utilities. The Master Plan includes a series of phased projects that will replace facilities in the oldest part of the Laboratory, increase the reliability of the power supply for the Central Research and Administration Area, and improve the capacity needed for the East Canyon Area.

- Mechanical Utilities. The Master Plan includes the systematic replacement of mechanical utilities. Mechanical systerns undergoing rehabilitation include natural gas, domestic water, cooling water, low-conductivity water, storm drains, sanitary sewer, compressed air, and vacuum systems. Many of the mechanical utilities are up to 40 years old, and many are undersized for current laboratory demands.

\section{Management Considerations}

LBL's site-planning management issues focus on developing the strategic framework for structures and utilities necessary to achieve the Laboratory's mission safely and protect the environment. These issues include improving the reliability of utility systems, ensuring a safe working environment, restoring and rehabilitating obsolete buildings, consolidating support functions, and accommodating the increasing numbers of scientific guests and visitors using LBL's national research facilities.

Many of LBL's site-development issues stem from an obsolete, deteriorated infrastructure constructed during World War II and the immediate postwar period. During the past several years, DOE has begun significant investments to correct deficiencies in mechanical and electrical utility systems and programmatic facilities for materıals research. A five-year construction plan for programmatic and general-purpose facilities is provided in Table 1 and major projects are identified in Map 4 (see Appendix). 


\section{LAWRENCE BERKELEY LABORATORY FIVE-YEAR CONSTRUCTION PLAN FY 1994 . FY 1998}

Flve-Year Plan for Programmatlc and General Purpose Facilltles, Inoluding Funded, Budgeted and Proposed Construction (FY BA, SM)

\begin{tabular}{|c|c|c|c|c|c|c|c|c|c|c|c|c|}
\hline Project & TEC & 1991 & 1992 & 1993 & 1894 & 1095 & 1906 & 1967 & 1008 & 1999 & 2000 & 2001 \\
\hline $\begin{array}{l}\text { FUNDED PROGRAM RELATED PROJECTS: } \\
\text { Advanced Light Source }\end{array}$ & 99.5 & 23.0 & 6.4 & & & & & & & & & \\
\hline $\begin{array}{l}\text { FUNDED MEL-FS PROJECTS (KG): } \\
\text { Envir Health \& Salety Proj (ER Program) } \\
\text { Original Labsile Substalion } \\
\text { Instrument Support Laboratory Rehabilitation } \\
\text { Sliope and Seismic Stabilization } \\
\text { Bullding } 90 \text { Seismic Rehabilitallon } \\
\text { East Canyon Electrical Salely Project } \\
\text { Rool Replacements, Phase I } \\
\text { SUBTOTAL. FUNDED MEL.FS PROJECTS }\end{array}$ & $\begin{array}{r}13.2 \\
3.0 \\
2.1 \\
3.7 \\
6.8 \\
3.9 \\
2.5 \\
35.2\end{array}$ & $\begin{array}{l}1.6 \\
0.0 \\
0.0 \\
2.4 \\
3.7\end{array}$ & $\begin{array}{r}0.5 \\
2.7 \\
1.9 \\
0.8 \\
2.7 \\
0.4 \\
2.0 \\
11.0\end{array}$ & $\begin{array}{l}0.4 \\
1.5 \\
0.5 \\
3.9\end{array}$ & $\begin{array}{l}20 \\
4,0\end{array}$ & & & & & & & \\
\hline $\begin{array}{l}\text { FUNDED ERWM PROJECTS: } \\
\text { Hazardous Wasle Handling Facility } \\
\text { Envir Health \& Salely Proj (ERWM Program) } \\
\text { SUBTOTAL - FUNDED ERWM PROJECTS }\end{array}$ & $\begin{array}{r}12.0 \\
1.8 \\
13.8\end{array}$ & $\begin{array}{l}0.0 \\
0.0 \\
0.0\end{array}$ & $\begin{array}{l}1.6 \\
0.0 \\
1.6\end{array}$ & $\begin{array}{l}0.0 \\
0.0 \\
0.0\end{array}$ & $\begin{array}{l}5, \\
07 \\
6,5\end{array}$ & & & & & & & \\
\hline TOTAL FUNDED & 148.5 & 30.7 & 19.0 & 3.9 & 10.5 & & & & & & & \\
\hline $\begin{array}{l}\text { BUDGETED MEL-FS PROJECTS (KG) } \\
\text { Salety \& Support Services Facility } \\
\text { Fire \& Salety Systems Upgrade Proj, Ph I } \\
\text { Rehab of Site Mech Uili, Ph II. Sewer Moniloring } \\
\text { Hazardous Malerials Saleguards, Ph I }\end{array}$ & $\begin{array}{l}9.9 \\
4.6 \\
7.1 \\
5.1\end{array}$ & & & $\begin{array}{l}3.0 \\
1.5 \\
0.8 \\
1.5\end{array}$ & $\begin{array}{l}4,5 \\
2,0 \\
3,4 \\
3,6\end{array}$ & $\begin{array}{l}2.4 \\
2.1 \\
2.0\end{array}$ & & & & & & \\
\hline TOTAL BUDGETED MEL.FS PROJECTS & 26.7 & 0.0 & 0.0 & 6.8 & 13.5 & 6.4 & & & & & & \\
\hline TOTAL FUNDED and BUDGETED & 175.2 & 30.7 & 19.0 & 10.7 & 24.0 & 6.4 & & & & & & \\
\hline $\begin{array}{l}\text { PROPOSED PROGRAM REL ATED PROJECTS: } \\
\text { Human Genome Laboralory (KP) } \\
\text { Chemical Dynamics Research Laboratory (KC) } \\
\text { Induction Linac Systems Experiment (AT) } \\
\text { ALS Lile Sciences Center } \\
\text { Bldg } 6 \text { 2nd Floor ALS User Space Improvements } \\
\text { Advanced Lighl Source, Beamline Initiative (KC) } \\
\text { SUBTOTAL. PROPOSED PROGRAM RELATED }\end{array}$ & $\begin{array}{r}24.9 \\
104.6 \\
64.4 \\
7.9 \\
\text { (TBD) } \\
42.3 \\
244.1\end{array}$ & 0.0 & 0.0 & 0.0 & $\begin{array}{r}2.2 \\
117 \\
0.6 \\
0.8 \\
6.0 \\
30.0\end{array}$ & $\begin{array}{r}158 \\
28.2 \\
20.5 \\
4.8 \\
12.0 \\
813\end{array}$ & $\begin{array}{r}5.9 \\
29.8 \\
15.1 \\
2.6 \\
14.0 \\
67.4\end{array}$ & $\begin{array}{r}10 \\
24,4 \\
115 \\
\\
103 \\
47.2\end{array}$ & $\begin{array}{r}10,5 \\
7.7 \\
9 \\
18.2\end{array}$ & & & \\
\hline 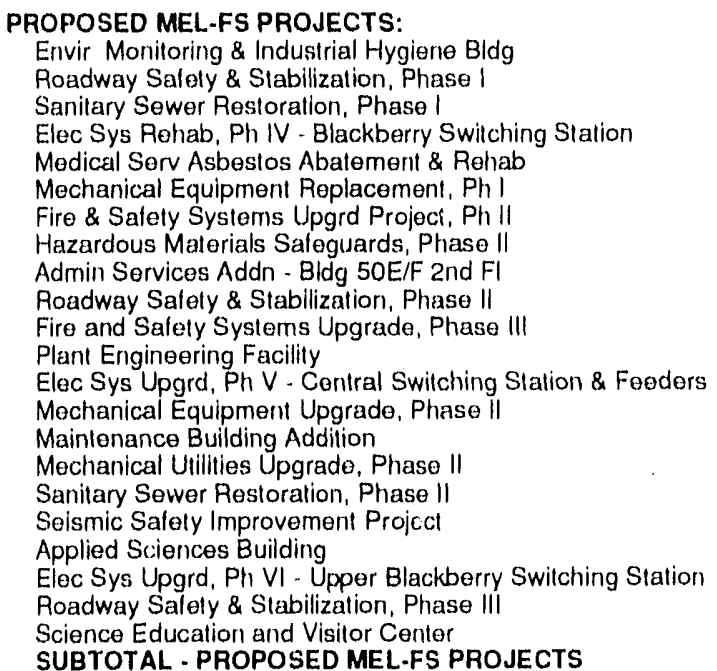 & $\begin{array}{r}20.1 \\
5.5 \\
2.1 \\
5.6 \\
2.1 \\
3.8 \\
4.0 \\
6.5 \\
6.0 \\
4.7 \\
5.0 \\
9.0 \\
5.5 \\
4.0 \\
5.0 \\
6.0 \\
4.0 \\
4.0 \\
20.0 \\
6.7 \\
6.0 \\
8.0 \\
143.6\end{array}$ & 0.0 & 0.0 & 0.0 & $\begin{array}{l}15 \\
0,6 \\
0.2 \\
0.6 \\
0.4 \\
0.4\end{array}$ & $\begin{array}{l}0.5 \\
21 \\
1.8 \\
2.8 \\
17 \\
3.4 \\
04 \\
06 \\
06 \\
0.5\end{array}$ & $\begin{array}{r}151 \\
28 \\
01 \\
2,3 \\
2,1 \\
28 \\
3.6 \\
46 \\
05 \\
0.9 \\
0.5 \\
0.4 \\
\end{array}$ & $\begin{array}{l}1,5 \\
3,1 \\
16 \\
26 \\
4,5 \\
30 \\
25 \\
0,5 \\
0,6 \\
0,4 \\
0.4\end{array}$ & $\begin{array}{r} \\
\\
\\
2,0 \\
3,6 \\
2,0 \\
1,5 \\
3.5 \\
2,1 \\
2,0 \\
2.07 \\
0.6 \\
0,8 \\
23,2\end{array}$ & $\begin{array}{r}2.0 \\
2.1 \\
1.5 \\
1.5 \\
1.0 \\
3.0 \\
3.6 \\
4.5 \\
19.2\end{array}$ & $\begin{array}{r}12.0 \\
3.0 \\
1.8 \\
2.7 \\
19.5\end{array}$ & 5.0 \\
\hline
\end{tabular}

Escalaled at $2.5 \%$, FY'92; $3.9 \%$, FY' $93 ; 4.7 \%$, FY' $94 ; 4.8 \%, F Y^{\prime} 95 ; 4.9 \%, F Y^{\prime} 96 ; 4.9 \%, F Y^{\prime} 97 ; 5.0 \%, F Y^{\prime} 98 ; 5.1 \%, F Y^{\prime} 99 ; 5.2 \%, F^{\prime} 00 ;$ and $5.3 \%, F Y^{\prime} 01$

- TEC includes costs prior to 1991 
The facilities issues being addressed by LBL and DOE during the five-year construction planning period include:

- Programmatic Facilities. Programmatic facilities primarily provide capability for DOE's Office of Energy Research. These facilities projects include the Chemical Dynamics Research Laboratory, Human Genome Laboratory, and the completion of existing space and additions for the ALS Life Sciences Center, ALS user facilities, and the ALS Beamline Initiative. Other programmatic projects include additions for heavy-ion accelerator research 'the Induction Linac Systems Experiment), cell and molecular biology, biomedical isotope facilities, and magnetic fusion energy ion source test stands. Each programmatic facility, like general-purpose facilities, integrates NEPA, CEQA, environment, safety and health considerations into design and project review from the early conceptual phases through completion of construction and operation.

- Accelerator Improvement Projects. The Bevalac modernization program includes the installation of new controls and control systems for enhanced overall performance of the accelerator. The installation of the Electron Cyclotron Resonance (ECR) source at the 88-Inch Cyclotron has resulted in greater than fivefold increase in beam intensity. Design efforts for the next-generation, gyrotrondriven ECR source are under way. Improvement funds will be provided for additions to the ALS Project. These additions will enhance experimental equipment aud beamline components, provide photon beam stabilization, and include accelerator system upgrades to improve performance.

- Environmental Restoration and Waste Management (ERWM). LBL environment? management site projects and operating activities are essential to correct and restore environmental conditions and to improve the management of waste handling operations in support of DOE's national environmental objectives. The five-year ERWM Plan incli:des a corrective action program to achieve and maintain required exposure and risk levels to chemicals in soils and groundwater, in discharges to sewers, and in laboratory buildings. The environmental restoration program for facilities includes the assessment and remediation of chemical contamination, the closure of th: existing hazardous waste handling facility, and planned D\&D activities for the Bevalac. The wa'ste management prograrn includes support for the construction of a new hazardous waste handling facility, the development of an aggressive waste minimization program and other projects. These ERWM project plans provide for continuing environmental protection for compliance with DOE and other Federal regulations and for meeting requirements established by state and loca! agencies.

- Safety and Health (S\&H) Plan. The Laboratory is preparing a detailed Safety and Health 5 Year Plan for the FY 1994 budget process. The prioritized plan will strengthen DOE S\&H management and improve the allocation of $\mathrm{S} \& \mathrm{H}$ resources.

- Inactive Surplus Facilities Plan. The development of new program directions for Nuclear Physics will result in the phase-out of LBL's Bevalac nuclear physics program in FY 1994. Unless support for the Space Exploration Initiative warrants continued use or funding is provided from another agency, the Bevalac will undergo decommissioning in accordance with the FY 1992-1997 LBL Decommissioning Plan. The major costs for decommissioning will be borne by ERWM. Associated preparation and transfer costs prior to ERWM acceptance will be borne by the Office of Energy Research.

- Multiprogram Energy Laboratory Facility Support (MEL-FS). The total proposed five-year (FY 1994FY 1998) MEL-FS program will require budget authority of $\$ 100 \mathrm{M}$ for this period. This modernization program addresses needs primarily related to the many buildings and utilities that are 20-40 years old and need improved safety, mechanical, electrical, and structural systems to meet current design standards. Full modernization of the main site requires a long-term 20-year investment program. Individual projects are evaluated against generic Laboratory SDP priorities: (1) safety systems and safety facilities, (2) environmental protection, (3) utilities reliability, (4) design standards and obsolescence, and (5) delivery of research and support services. 
MEL-FS Building Replacement and Rehabilitation-During the next five years LBL's modernization plans call for construction to improve the safety and support services infrastructure and to improve general-purpose mechanical- and electrical-engineering facilities. The plan includes removal of obsolete, inefficient, and substandard facilities that cannot be made adequate and replacement of temporary structures for support activities.

MEL-FS Safety Improvements-Safety and Health improvements began in FY 1988 and include: fire protection upgrades; hazardous materials control upgrades; removal of asbestos; and improvements to safety services, medical services, building illumination, radiation protection, water-pollution control, and monitoring. Seismic stabilization of steep slopes began in FY 1991. Road improvements include widening, replacement of base materials, and elimination of acute curves and blind spots.

MEL-FS Electrical Utilities - In the next five years, the LBL main-site electrical power system rehabilitation plan calls for the completion of the first four phases and work to begin on the remaining two phases. This six-phase program will result in the complete rehabilitation of the underground 12-kV power distribution system and the installation of six new circuit breaker switching stations throughout the site. The upgraded switching and distribution system will provide the reliability, flexibility, and expandability necessary for efficient Laboratory operation and future growth.

MEL-FS Mechanical Utilities - Mechanical utilities comprise domestic and cooling water, storm drains and sanitary sewers, natural gas, compressed-air, and vacuum systems. These utilities are up to 40 years old, and many are undersized for current Laboratory demands. The modernization plans provide for the orderly replacement of these utilities and will help prevent potential damage to the environment. Scheduled utilities improvements only correct existing deficiencies; any delays will engender further deterioration of these essential utilities.

Decommissioning Plan-The development of new program directions for Nuclear Physics will result in the phase-out of LBL's Bevalac nuclear physics program in FY 1994. Unless support for the NASA Space Exploration Initiative warrants continued use, the Bevalac will undergo decommissioning in accordance with the FY 1992-1997 LBL Decommissioning Plan. The major program costs for decommissioning will be borne by ERWM. Associated preparation and transfer costs prior to ERWM acceptance will be borne by the Office of Energy Research.

- General Plant Projects (GPP). GPP funds have been provided by DOE's Nuclear Physics Division to fund priority construction projects that have a funding ceiling of $\$ 1.2 \mathrm{M}$. Funding to date has been inadequate to meet the Laboratory needs in a timely schedule. This program has a significant backlog of projects exceeding $\$ 20 \mathrm{M}$. Roughly a third of this backlog is for environment, health, and safety needs; a third is for utilities safety and reliability, building maintenance, and standards compliance; and a third for multiprogram support facilities and small programmatic projects and additions. In FY 1992 more than half of the \$3.1 M GPP budget will be used for ES\&H-related projects. The remaining funds cannot meet current project needs and do not allow progress in reducing this backlog. Increasing GPP funding to $\$ 6 \mathrm{M}$ annually and increasing the ceiling from $\$ 1.2 \mathrm{M}$ to $\$ 2.0 \mathrm{M}$ would ensure the success of the Laboratory's safety rehabilitation program and help reduce the current backlog of projects over the next five years. Support and coordination for both programmatic and institutional GPP through the Office of Energy Research would facilitate effective management of GPP needs.

- General Purpose Equipment (CPE). Essential support equipment has been funded through DOE's Nuclear Physics Division. LBL's Five-Year GPE Plan identifies needs based on a range of criteria, including environment, safety, and health; legal requirements; failed, worn, inefficient, or obsolete equipment; substandard performance; or increased workload and demand. The current funding level of $\$ 1.7 \mathrm{M} /$ year is inadequate to meet the Laboratory needs. Currently there is a $\$ 38 \mathrm{M}$ equipment backlog for environmental monitoring and fire safety, physical-plant maintenance, mechanical and electrical shops, transportation, and data processing and communications. Increasing GPE support $\$ 3 \mathrm{M}$ /year would provide a basis for reducing the backlog. Consolidated GPE management at the level of the Office of Energy Research would facilitate the implementation of an integrated and longer-range GPE plan. 
Appendix: LBL Maps 


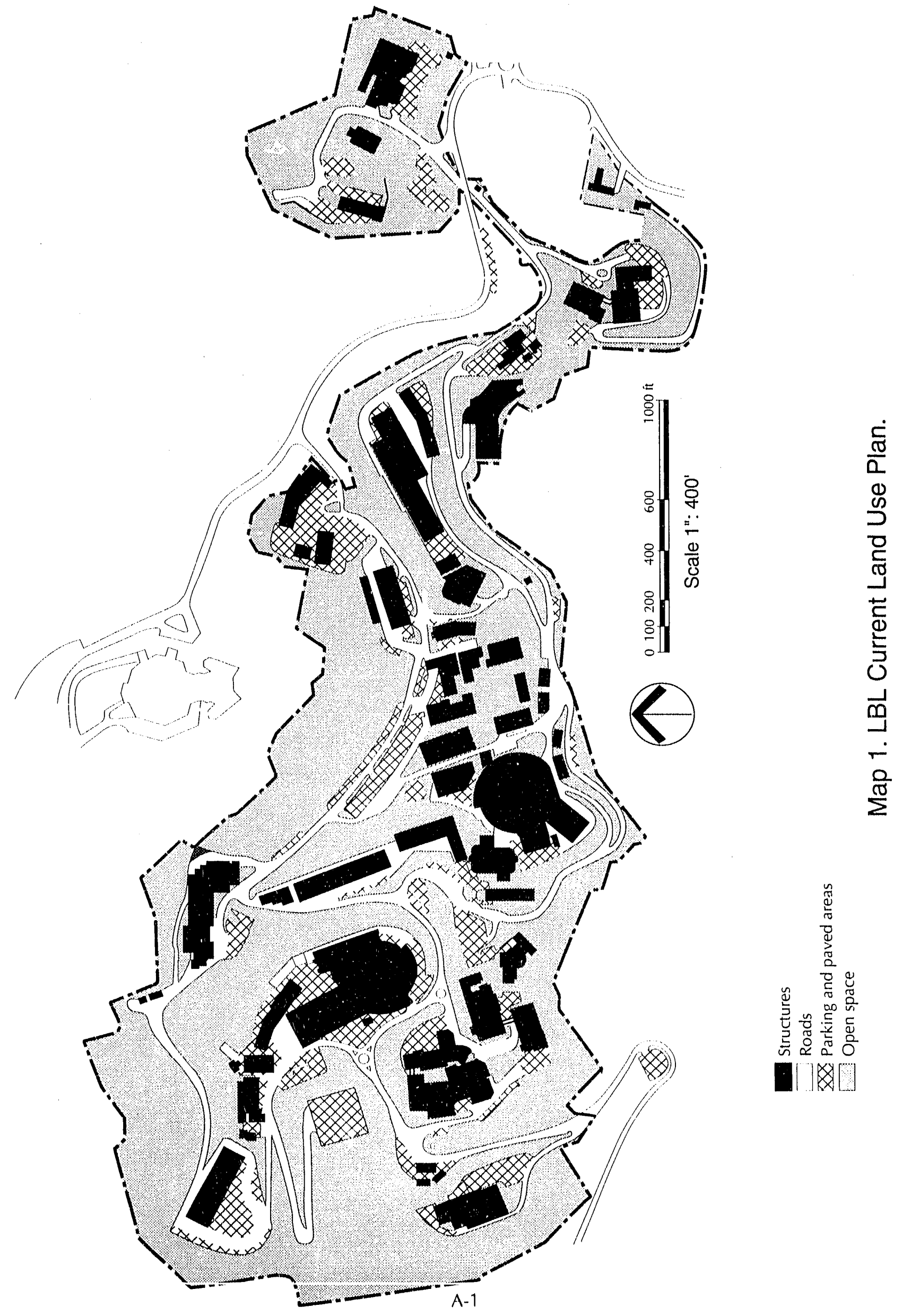




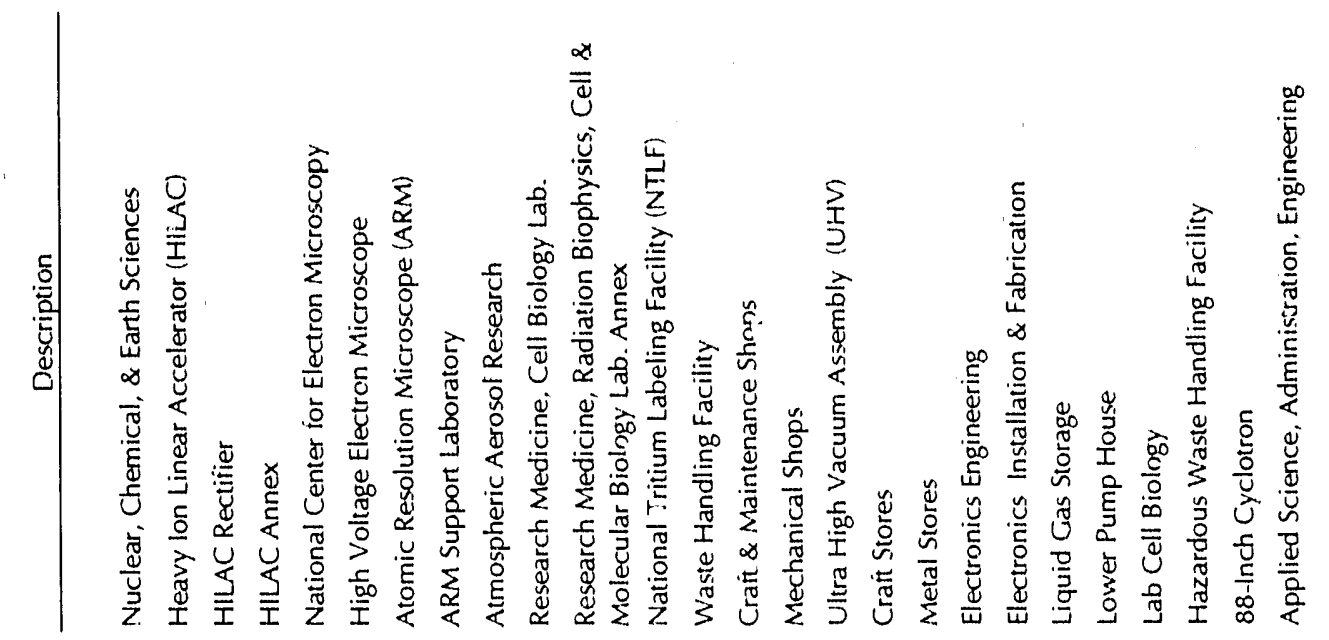

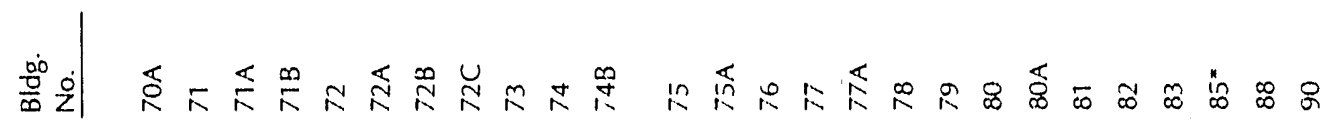

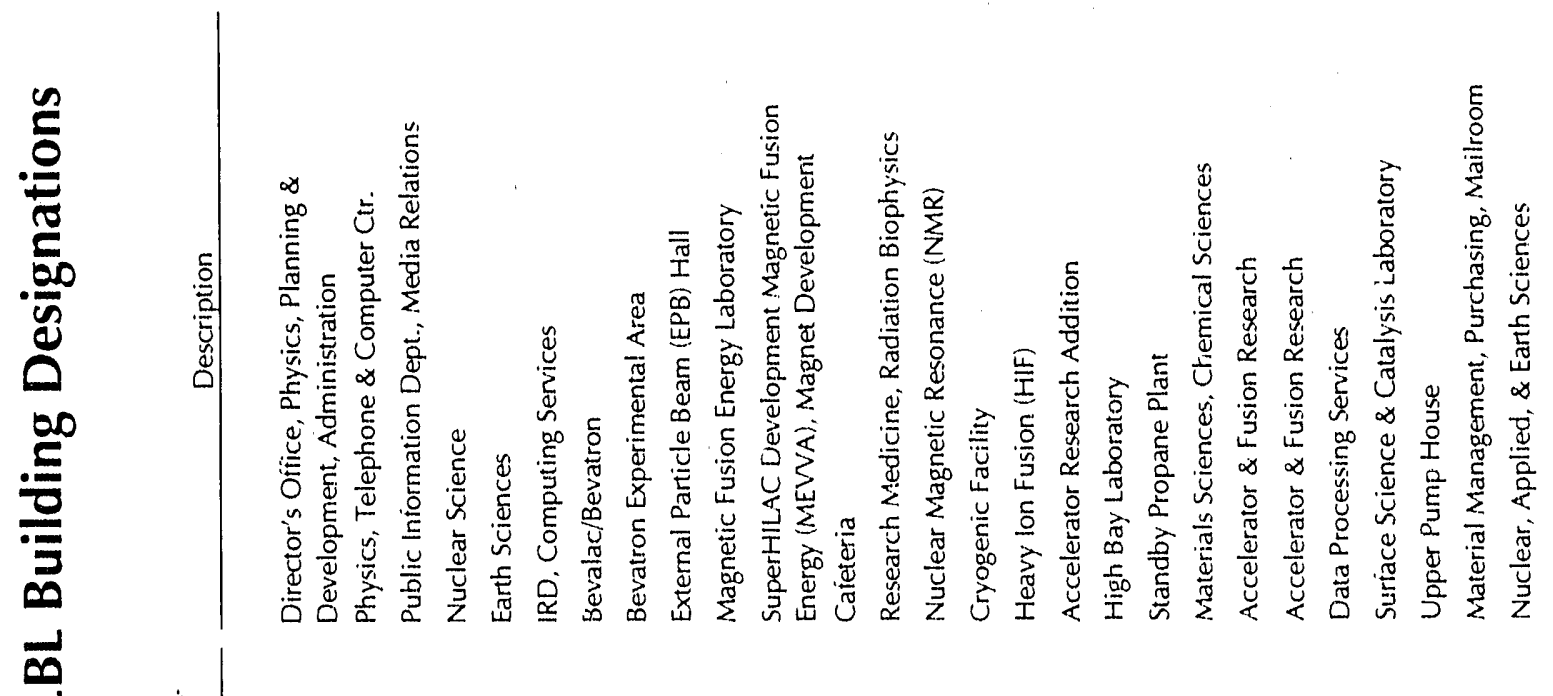

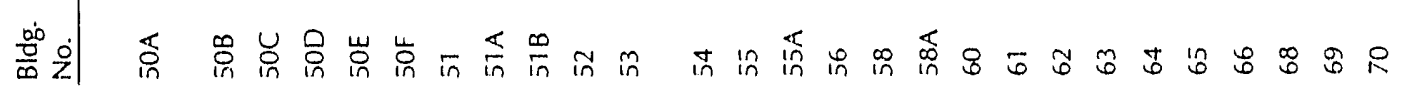

|

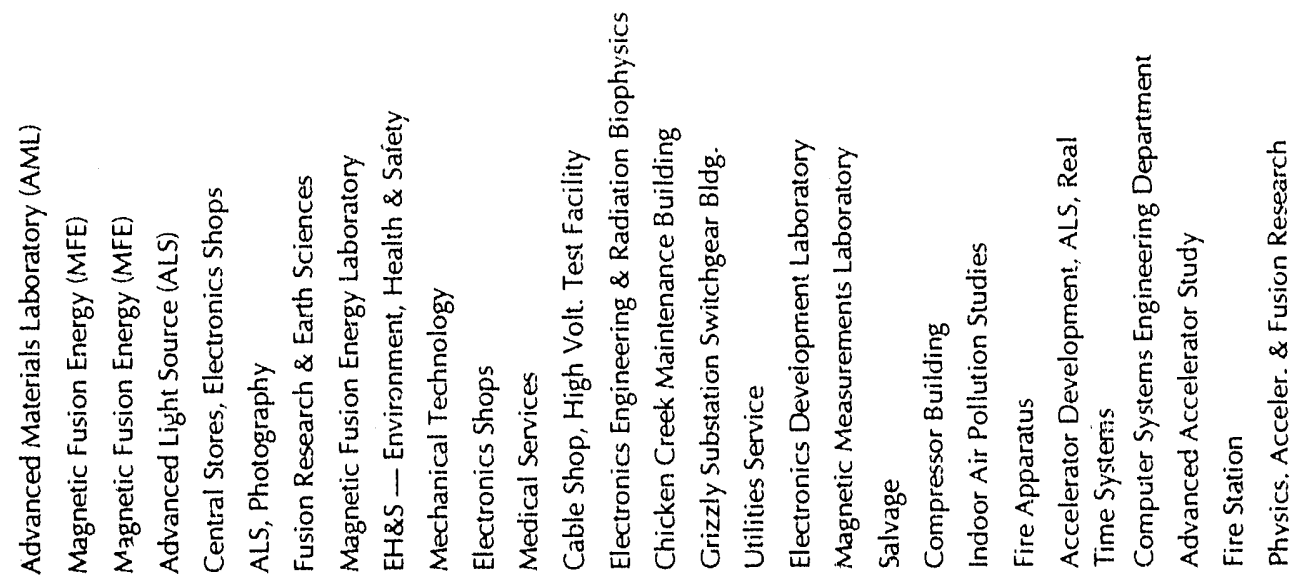

咅家 N 


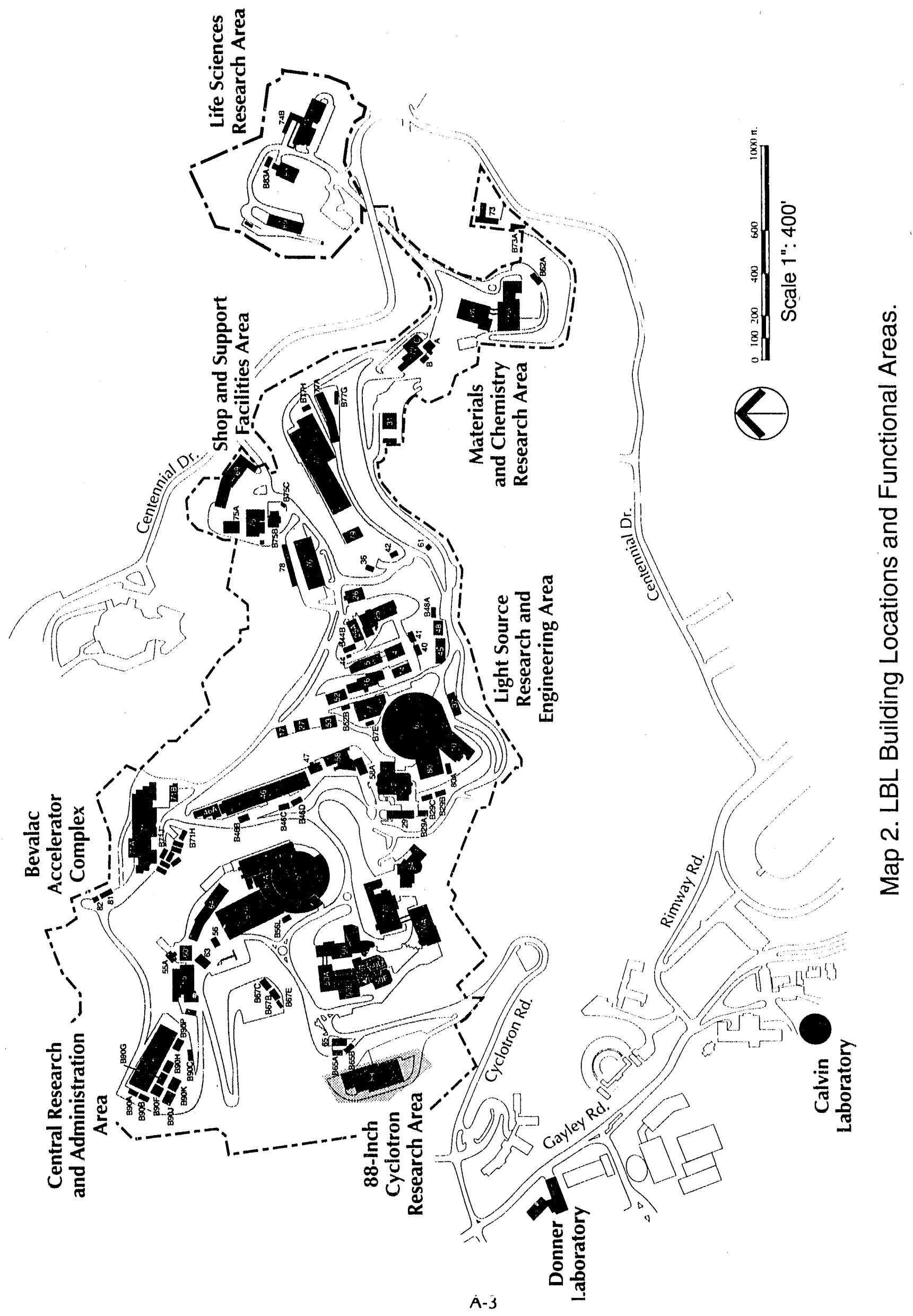




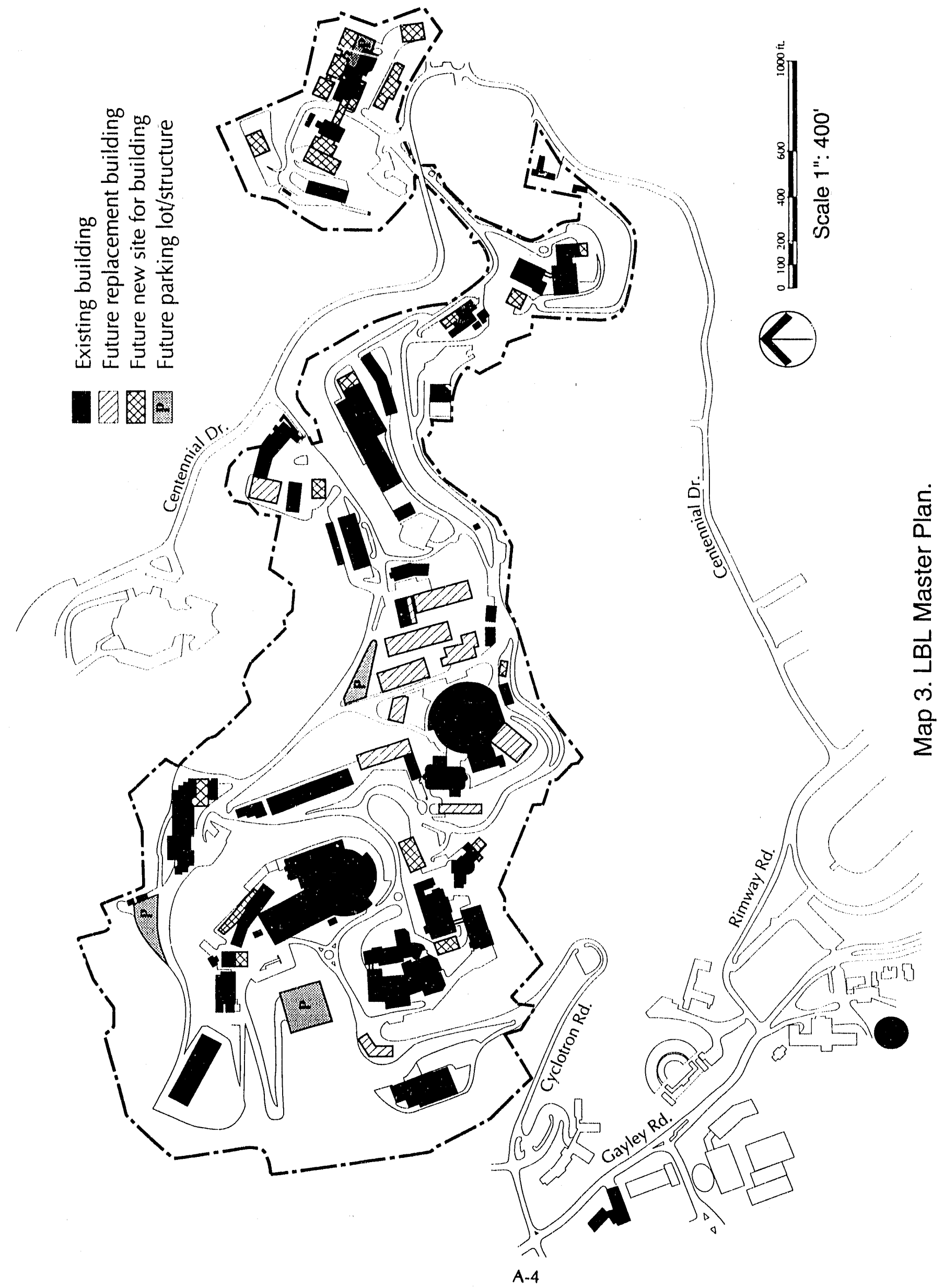




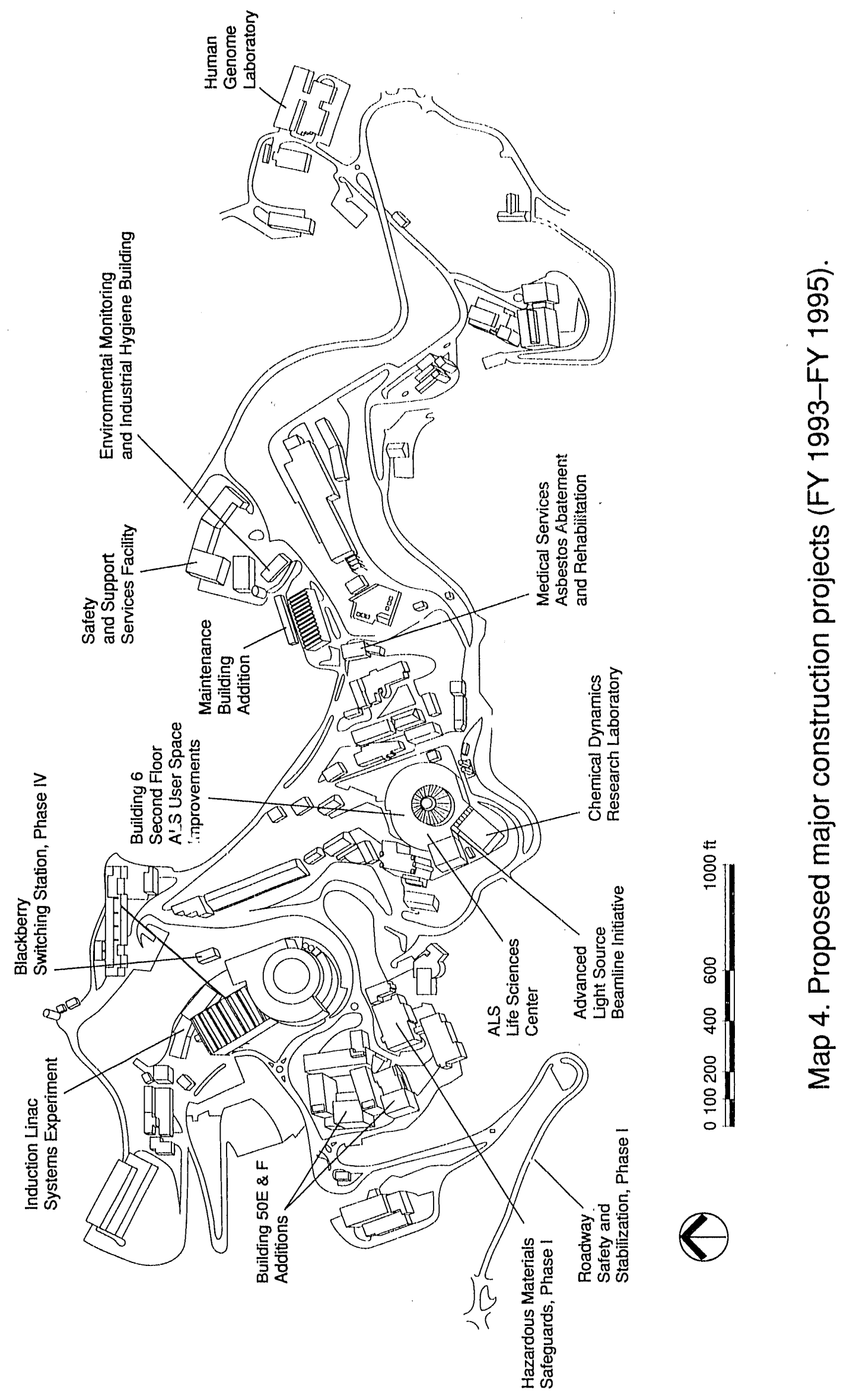



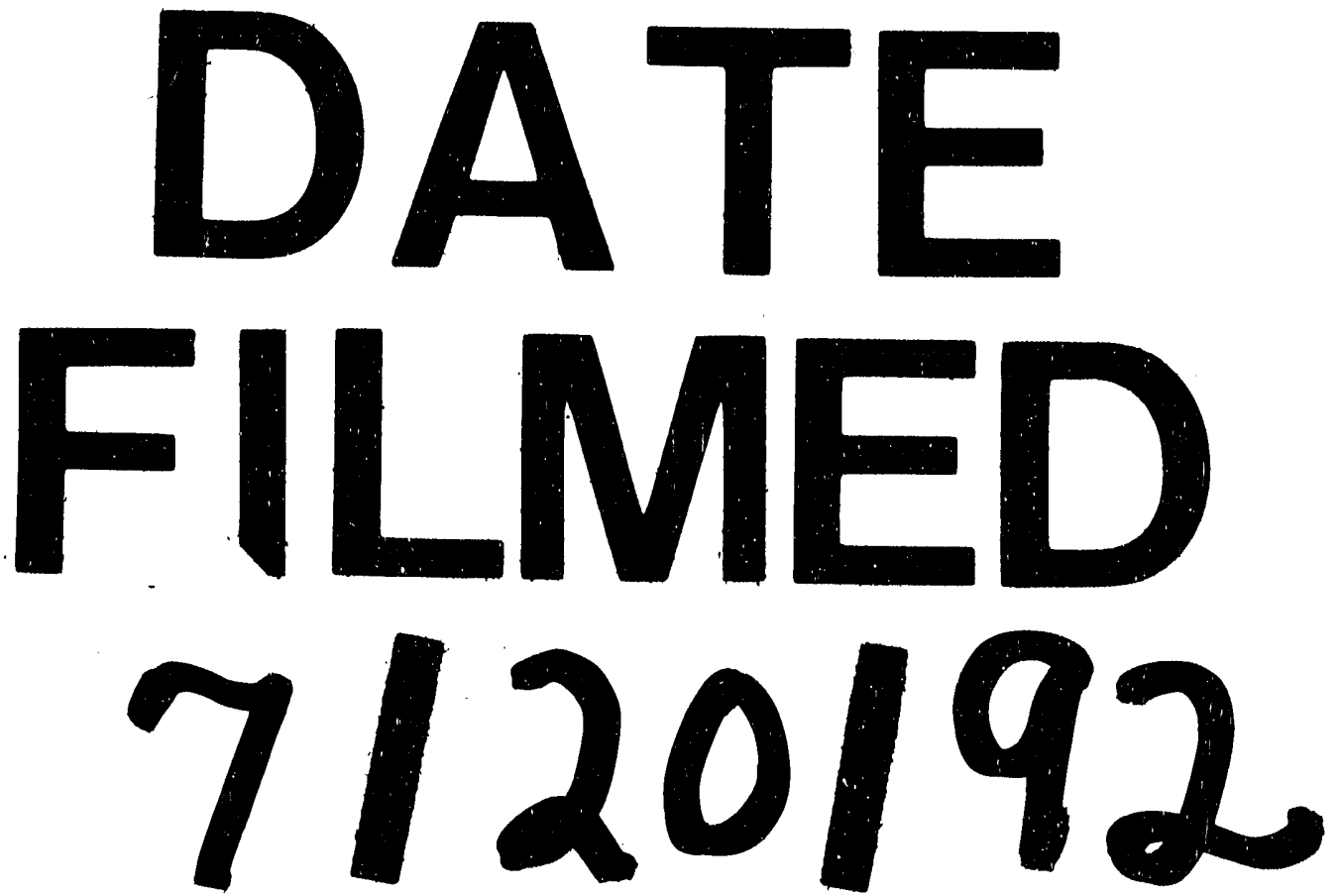
